\title{
Semi-rational engineering of cellobiose dehydrogenase for improved hydrogen peroxide production
}

Christoph Sygmund ${ }^{1}$, Paul Santner ${ }^{1}$, Iris Krondorfer ${ }^{1}$, Clemens K Peterbauer ${ }^{1}$, Miguel Alcalde ${ }^{2}$, Gibson S Nyanhongo ${ }^{3}$, Georg M Guebitz ${ }^{3}$ and Roland Ludwig ${ }^{1 *}$

\begin{abstract}
Background: The ability of fungal cellobiose dehydrogenase (CDH) to generate $\mathrm{H}_{2} \mathrm{O}_{2}$ in-situ is highly interesting for biotechnological applications like cotton bleaching, laundry detergents or antimicrobial functionalization of medical devices. CDH's ability to directly use polysaccharide derived mono- and oligosaccharides as substrates is a considerable advantage compared to other oxidases such as glucose oxidase which are limited to monosaccharides. However CDH's low activity with oxygen as electron acceptor hampers its industrial use for $\mathrm{H}_{2} \mathrm{O}_{2}$ production. A CDH variant with increased oxygen reactivity is therefore of high importance for biotechnological application. Uniform expression levels and an easy to use screening assay is a necessity to facilitate screening for $\mathrm{CDH}$ variants with increased oxygen turnover.
\end{abstract}

Results: A uniform production and secretion of active Myriococcum thermophilum $\mathrm{CDH}$ was obtained by using Saccharomyces cerevisiae as expression host. It was found that the native secretory leader sequence of the cdh gene gives a 3 times higher expression than the prepro leader of the yeast a-mating factor. The homogeneity of the expression in 96-well deep-well plates was good (variation coefficient $<15 \%$ ). A high-throughput screening assay was developed to explore saturation mutagenesis libraries of $c d h$ for improved $\mathrm{H}_{2} \mathrm{O}_{2}$ production. A 4.5-fold increase for variant N700S over the parent enzyme was found. For production, N700S was expressed in P. pastoris and purified to homogeneity. Characterization revealed that not only the $k_{\text {cat }}$ for oxygen turnover was increased in N700S (4.5-fold), but also substrate turnover. A 3-fold increase of the $k_{\text {cat }}$ for cellobiose with alternative electron acceptors indicates that mutation N700S influences the oxidative- and reductive FAD half-reaction.

Conclusions: Site-directed mutagenesis and directed evolution of $\mathrm{CDH}$ is simplified by the use of $\mathrm{S}$. cerevisiae instead of the high-yield-host $P$. pastoris due to easier handling and higher transformation efficiencies with autonomous plasmids. Twelve clones which exhibited an increased $\mathrm{H}_{2} \mathrm{O}_{2}$ production in the subsequent screening were all found to carry the same amino acid exchange in the cdh gene (N700S). The sensitive location of the five targeted amino acid positions in the active site of CDH explains the high rate of variants with decreased or entirely abolished activity. The discovery of only one beneficial exchange indicates that a dehydrogenase's oxygen turnover is a complex phenomenon and the increase therefore not an easy target for protein engineering.

\footnotetext{
* Correspondence: roland.ludwig@boku.ac.at

${ }^{1}$ Vienna Institute of Biotechnology, Department of Food Sciences and

Technology, BOKU-University of Natural Resources and Life Sciences, Vienna,

Austria

Full list of author information is available at the end of the article
}

\section{Biomed Central}

(C) 2013 Sygmund et al.; licensee BioMed Central Ltd. This is an Open Access article distributed under the terms of the Creative Commons Attribution License (http://creativecommons.org/licenses/by/2.0), which permits unrestricted use, distribution, and reproduction in any medium, provided the original work is properly cited. 


\section{Background}

The extracellular fungal flavocytochrome cellobiose dehydrogenase $(\mathrm{CDH}, \mathrm{EC}$ 1.1.99.18) is secreted by wooddegrading, phytopathogenic and saprotrophic fungi [1]. The widespread appearance implies an important function of $\mathrm{CDH}$ in the process of wood degradation [2-5]. It is a monomeric protein consisting of two domains [6,7], which oxidizes several carbohydrates at the flavodehydrogenase domain carrying an FAD cofactor. A smaller, heme $b$ containing cytochrome domain is connected via a flexible linker. A typical CDH consists of approximately 800 amino acids. In some ascomycetous CDHs, like the one from Myriococcum thermophilum (828 aa) used in this study, a family 1 carbohydrate binding module (CBM1) is additionally attached to the $\mathrm{C}$-terminus. The molecular mass ranges from 85 up to $101 \mathrm{kDa}$ depending on the degree of glycosylation, which can account for up to $20 \%$ of the molecular mass $[8,9]$. Basidiomycetous CDHs show a high specificity for cellobiose and cello-oligosaccharides, whereas some ascomycetous CDHs like $M$. thermophilum $\mathrm{CDH}$ have a broader substrate specificity and oxidize also other mono-, di- and oligosaccharides, albeit with lower catalytic efficiency $[1,5,9,10]$. During the reductive halfreaction the FAD cofactor oxidizes suitable carbohydrates at the anomeric $\mathrm{C} 1$ atom into intermediary lactones, which hydrolyze spontaneously to the corresponding aldonic acids (Figure 1). Re-oxidation of the FAD can be performed by either two-electron acceptors (quinones, 2,6-dichloroindophenol, phenoxazine- and phenothiazine dyes) or by one-electron acceptors (polysaccharide monooxygenases, cytochrome $c$, ferricyanide and ferrocenium) or very slowly by oxygen $[3,4,9]$.

Due to its versatile properties $\mathrm{CDH}$ has been applied in biosensors for the detection of lactose, glucose and catecholamines, in enzymatic biofuel cells as anode catalyst $[8,11]$, for the production of lactobionic acid [12-14], as well as in biodegradation [15] and bioremediation [16]. A more recent proposed application of $\mathrm{CDH}$ has been the in situ production of $\mathrm{H}_{2} \mathrm{O}_{2}$ for cotton bleaching $[10,17,18]$. $\mathrm{CDH}$ has the potential to replace the currently used mixture of $\mathrm{H}_{2} \mathrm{O}_{2}$ and $\mathrm{NaOCl}$, which causes damage to the cotton fibres, forms toxic by-products and consumes large amounts of energy and water. In the proposed eco-friendly bleaching system, $\mathrm{CDH}$ produces the reactive oxygen species. The suitability of $\mathrm{CDH}$ for this approach was demonstrated [18]. In contrast to other proposed biocatalysts like choline oxidase [19] or glucose oxidase [20] CDH can produce $\mathrm{H}_{2} \mathrm{O}_{2}$ by oxidation of a wide range of carbohydrates (cellulose and cellodextrins, galactomannans, lactose, maltose or glucose) which occur in the process (e.g. from starch desizing), are added or generated by cellulolytic enzymes [10]. Similarly, the potential of CDH for medical application was recently demonstrated $[21,22]$. The main drawback of $\mathrm{CDH}$ for these applications is its relatively

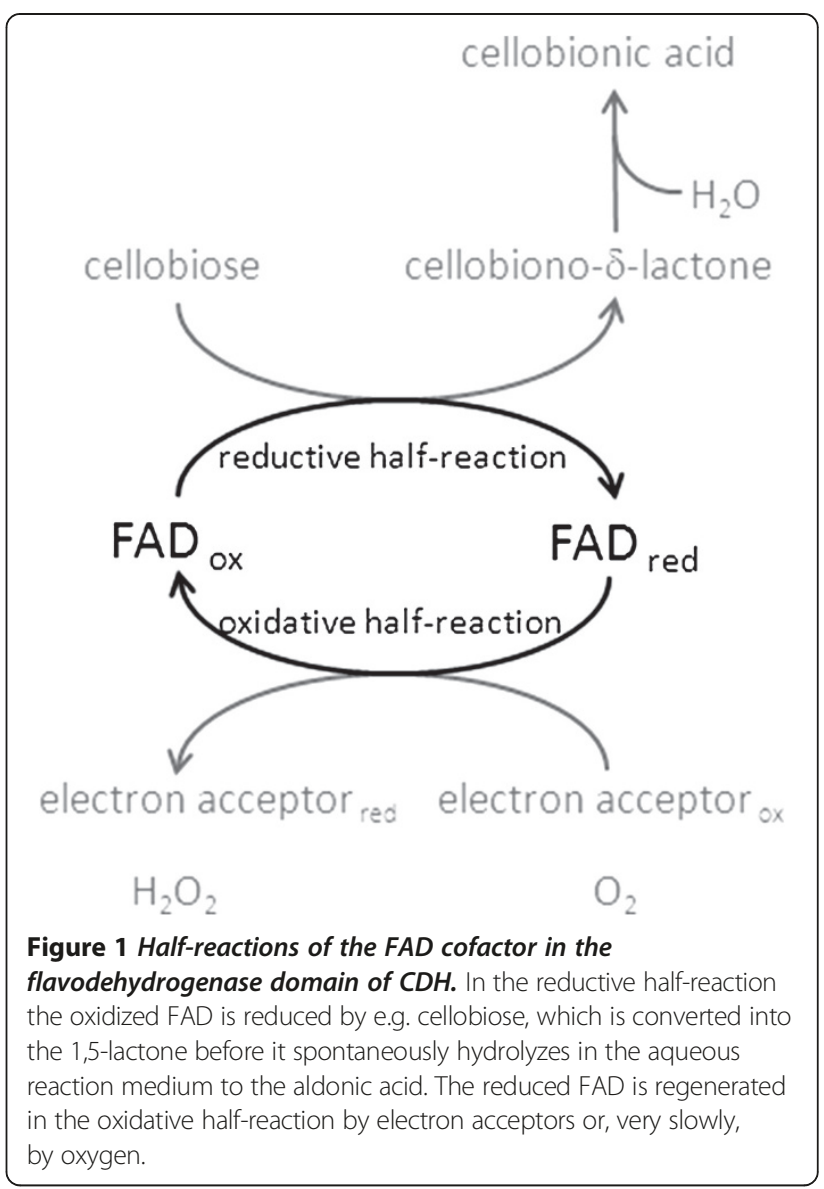

slow $\mathrm{H}_{2} \mathrm{O}_{2}$ production rate compared to oxidases. $\mathrm{CDH}$ with increased oxygen reactivity would combine the mentioned advantages with an increased $\mathrm{H}_{2} \mathrm{O}_{2}$ production. Such a CDH would be very attractive for the pulp \& paper industry, cotton-bleaching, consumer applications like laundry detergents or antimicrobial functionalization of medical devices, e.g., catheters.

The modulation of the oxygen reactivity in flavoenzymes is currently an active field of research. However, no definite guidelines exist on how to change a dehydrogenase into an oxidase or vice versa $[23,24]$. It has been shown that the protein matrix surrounding the flavin cofactor (FAD or FMN) has a great effect on the oxygen reactivity [25]. Therefore, semi-rational protein engineering, which targets amino acid residues in the catalytic-site in close vicinity to the FAD by saturation mutagenesis, was the applied strategy to increase the oxygen reactivity of $\mathrm{CDH}$. Several saturation mutagenesis libraries of the $M$. thermophilum $c d h$ gene for five target residues close to the FAD were constructed by the sequence overlap extension (SOE) method and functionally expressed in S. cerevisiae. A robust and easy to use high-throughput screening (HTS) assay was established to select $\mathrm{CDH}$ variants for improved 
$\mathrm{H}_{2} \mathrm{O}_{2}$ production. Finally, the mutated $c d h$ gene was recombinantly expressed in $P$. pastoris to prepare sufficient amounts of the $\mathrm{CDH}$ variant for kinetic characterization and evaluation of the assay.

\section{Results and discussion}

Expression of $M$. thermophilum $\mathrm{CDH}$ in S. cerevisiae

$\mathrm{CDH}$ is a secretory glycosylated fungal protein, and expression has so far only been successful in eukaryotic expression systems. During the last years, $P$. pastoris was established as the standard expression system for $\mathrm{CDH}$ [5,26-28]. Although it is a powerful host for recombinant protein production it is not considered as the preferred host organism for protein engineering by directed evolution. The lack of reliable episomal vectors along with modest transformation efficiencies, preclude in most of the cases the use of this yeast for such approaches. Indeed, no reports of semi-rational engineering or directed evolution of CDHs are published. Even the possibility to express the sole flavodehydrogenase domain of $\mathrm{CDH}$ in the prokaryotic expression system E. coli [29] has not triggered engineering studies. This can be explained by the essential role of the cytochrome domain for many applications $[8,10,15]$. So far, heterologous expression of a full length $\mathrm{CDH}$ can only be achieved in eukaryotic expression hosts. Therefore, one goal of this study was to establish $S$. cerevisiae as eukaryotic expression system for $\mathrm{CDH}$, which would allow screening for improved variants of full length $\mathrm{CDH}$. S. cerevisiae is one of the most successfully used host organisms for directed evolution of eukaryotic proteins due to high transformation efficiencies, easy genetic manipulation and secretion of the target proteins $[30,31]$. There are several reports in literature where the expression level of the target protein could be increased by the exchange of the native secretory leader sequence with the $\alpha$-factor prepro leader from $S$. cerevisiae, even subjecting the corresponding fusion gene to several rounds of evolution for improved secretion [32-35].

Therefore we evaluated in a preliminary experiment the influence of the signal sequence on the expression level of $\mathrm{CDH}$ in $S$. cerevisiae. Two nucleotide sequences coding for $M$. thermophilum $\mathrm{CDH}(r \mathrm{CDH})$ with different signal sequences were cloned into pJRoC30 for expression under the control of the GAL1 promoter. Plasmid pJRoC30$M t C D H-n a t$ encodes the full length $\mathrm{CDH}$ including its native secretory leader. In plasmid pJRoC30-MtCDH- $\alpha$ the native signal sequence was replaced by the $\alpha$-factor prepro leader. The resulting expression vectors were transformed into chemical competent $S$. cerevisiae cells. Ninety-six colonies of each transformation were picked and cultivated in 96-well deep-well plates. After $120 \mathrm{~h}$ of induction, supernatants were tested for $\mathrm{CDH}$ activity with the $(2,6-$ dichloroindophenol) DCIP assay. The construct with the native secretory leader $\left(0.05 \mathrm{U} \mathrm{mL}^{-1}\right)$ showed on average a 3.1 times higher DCIP activity compared to the construct with the $\alpha$-factor prepro leader $\left(0.016 \mathrm{U} \mathrm{mL}^{-1}\right)$. To test the uniformity of the expression levels in the 96-well deep-well plates the coefficient of variation was calculated (Figure 2). Both constructs showed a variation below 15\% which is acceptable for screening mutant libraries [36]. However, due to the higher expression levels, the expression cassette employing the native secretory leader was selected for further studies.

Library construction and high-throughput screening (HTS) A comparative (homology) model of $\mathrm{CDH}$ from $M$. thermophilum was constructed using the crystal structure of the Phanerochaete chrysosporium flavodehydrogenase domain as template (PDB accession code 1KDG, Figure 3). The local alignment of the sequences (see Additional file 1) has a sequence identity of $39 \%$ for the modeled flavodehydrogenase sequence (positions 251 - 829), whereas the overall sequence identity is only $35 \%$. The obtained model was carefully tested by local and global model quality check programs. Five amino acids in the catalytic-site close to the FAD were selected for saturation mutagenesis. Three amino acids (G323, A322 and L324) interact with FAD's isoalloxazine ring system and are in close vicinity of the C4a-N5 locus, which is proposed to be important for the reduction of molecular oxygen in FAD-dependent oxidases. Two amino acids (N700 and H701) are part of the catalytic subsite close to the isoalloxazine ring and fully conserved among CDHs. It was anticipated that mutations of H701, the general base, leads in case of any substitution to inactive variants which can be used to evaluate the mutagenesis method. Degenerated codons of the NNS type were used. The corresponding mutant libraries were double screened for $\mathrm{CDH}$ activity and expression with the DCIP-based assay and for $\mathrm{H}_{2} \mathrm{O}_{2}$ production with the ABTS-HRP coupled assay. The ABTS-HRP coupled assay was derived from a published method [18] by switching leucocrystal violet by ABTS and splitting the reaction into a $\mathrm{H}_{2} \mathrm{O}_{2}$ generating part and, after thermal deactivation of the enzyme variants, a colorimetric detection reaction. The DCIP-based assay showed that a large number of mutations at the selected positions result in inactive $\mathrm{CDH}$ variants: $55 \%$ at $\mathrm{G} 323,80 \%$ at $\mathrm{A} 322,34 \%$ at L324, 29\% at N700 and 99\% at H701. This demonstrates the importance of the targeted amino acids for enzymatic activity although folding and stability could also be affected. Amino acid H701 corresponds in terms of position to $\mathrm{H689}$ in P. chrysosporium $\mathrm{CDH}$ which has been proposed to act as catalytic base [7]. Its importance in the catalytic machinery is reflected by the highest number of inactive variants.

During the first screening round twelve variants at position N700 and seven variants at position G232 were selected due to an increased $\mathrm{H}_{2} \mathrm{O}_{2}$ production and subjected 

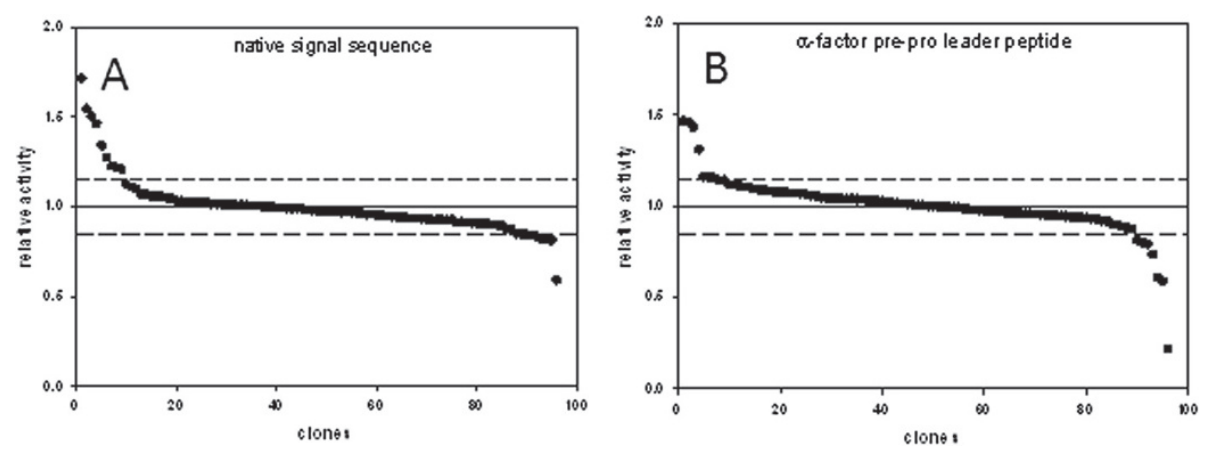

Figure 2 Landscapes of CDH expression levels. Dashed lines indicate the variation coefficient. S. cerevisiae cells were transformed with plasmid pJRoC30-MtCDH-nat (A) and pJROC30-MtCDH-a (B). 96 individual colonies of each transformation were cultivated under inducing conditions. Centrifuged supernatants were used for the DCIP-based assay.

to a re-screening. The increased $\mathrm{H}_{2} \mathrm{O}_{2}$ production could be confirmed for all N700 variants in the re-screening while the G232 variants turned out to be false positives. The twelve re-screened variants of position N700 showed an increased DCIP activity ( 4 times) as well as an increased $\mathrm{H}_{2} \mathrm{O}_{2}$ production ( $\sim$ times) compared to $r \mathrm{CDH}$. The sequencing results showed that all of them carried the mutation N700S. The amino acid serine was encoded by any of the 3 possible codons TCT, TCA and AGT, which demonstrates the good performance of the site-saturation mutagenesis method and the reliability of the screening assay.

\section{Production and purification of $M$. thermophilum $\mathrm{CDH}$ variant N700S in $P$. pastoris}

Although expression levels of $\mathrm{CDH}$ in $S$. cerevisiae $(0.05$ $\mathrm{U} / \mathrm{mL}$ ) were sufficient to perform the screening assay, they

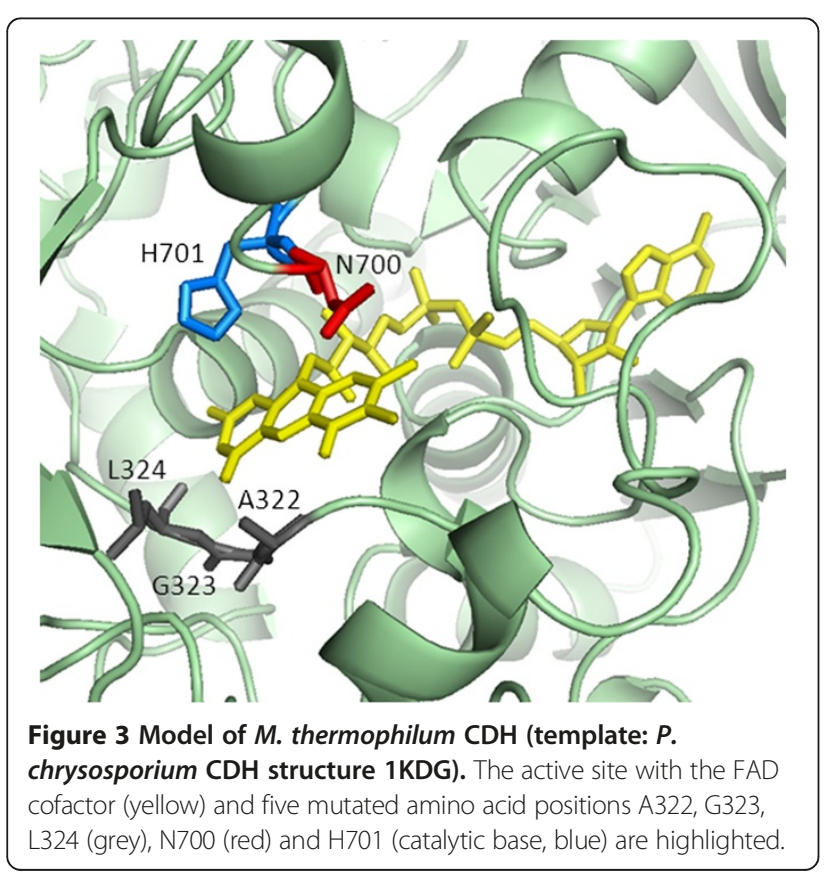

were low compared to reported expression levels of $\mathrm{CDH}$ using its standard recombinant expression host $P$. pastoris. Therefore we decided to use $P$. pastoris as production host for fermentation to obtain high amounts of $\mathrm{CDH}$ for protein purification. The mutation N700S was introduced into the P. pastoris expression plasmid pPICMtCDH by a two-step mutagenesis approach. The resulting plasmid was transformed into electro-competent P. pastoris cells. The enzyme was produced with a PCR verified clone in a 7-L stirred and aerated bioreactor. The volumetric $\mathrm{CDH}$ activity in the culture supernatant was measured with the DCIP assay and reached a maximum value of $1800 \mathrm{U} \mathrm{L}^{-1}$ after $123 \mathrm{~h}$. The recombinant enzyme was purified to apparent homogeneity using a two-step purification protocol (Table 1). Although only the purest fractions were pooled, $75 \%$ of the total activity was recovered. The homogeneous preparation consisted of $690 \mathrm{mg} \mathrm{CDH}$ (Figure 4A) with a specific DCIP activity of $8 \mathrm{U} \mathrm{mg}^{-1}$ and a high absorbance ratio $\mathrm{A}_{420} / \mathrm{A}_{280}$ of 0.54 , which was calculated from the $\mathrm{UV} / \mathrm{V}$ is absorption spectrum (Figure $4 \mathrm{~B}$ ) and is an indicator for the purity of the $\mathrm{CDH}$ sample [1]. The spectrum shows the typical increase of CDH's $b$-type heme $\alpha$ - and $\beta$-band at 562 and $533 \mathrm{~nm}$, respectively, the red-shift from 421 to $429 \mathrm{~nm}$ of the heme's Soret-band and the decrease of the FAD signal in the range of $450-500 \mathrm{~nm}$ upon reduction of $\mathrm{CDH}$ with a carbohydrate substrate.

\section{Oxygen reactivity}

The $\mathrm{O}_{2}$ consumption rates of variant N700S and $r \mathrm{CDH}$ were determined at $30^{\circ} \mathrm{C}$ using a fluorescence-based fiber optic sensor. This sensor does not consume $\mathrm{O}_{2}$ like a Clark-type electrode, which considerably reduces the oxygen concentration in small reaction volumes and therefore introduces a bias. Both enzymes were applied at the same protein concentration $\left(0.18 \mathrm{mg} \mathrm{mL}^{-1}\right)$. Variant N700S consumed all $\mathrm{O}_{2}$ present in the $1.9 \mathrm{~mL}$ microreactor $(2.3 \mu \mathrm{mol})$ in $100 \mathrm{~min}$, whereas the unmodified $r \mathrm{CDH}$ took $420 \mathrm{~min}$ (Figure 5 ). This increased oxygen reactivity 
Table 1 Purification scheme of CDH variant N700S

\begin{tabular}{lccccc}
\hline Purification step & Total activity $(\mathbf{U})$ & Total protein $(\mathbf{m g})$ & Specific activity $\mathbf{( U \mathbf { ~ m g } ^ { - 1 } )}$ & Yield (\%) & Purification (fold) \\
\hline Culture supernatant & 7380 & 3360 & 2.2 & 100 & 1 \\
\hline Phenyl-Sepharose & 5980 & 950 & 6.3 & 81 & 2.9 \\
\hline Q-Source & 5540 & 690 & 8.0 & 75 & 3.6 \\
\hline
\end{tabular}

was also verified by the stopped ABTS assay in cuvettes. While the fluorescence-based fiber optic sensor measures the decrease in oxygen concentration, the stopped ABTS assay indirectly detects the produced $\mathrm{H}_{2} \mathrm{O}_{2}$. One milligram of $r \mathrm{CDH}$ produced $0.028 \mu \mathrm{mol} \mathrm{H}_{2} \mathrm{O}_{2}$ per minute while variant N700S produced $0.127 \mu \mathrm{mol} \mathrm{H}_{2} \mathrm{O}_{2}$ per minute. Both methods showed that N700S converts $\mathrm{O}_{2}$ to $\mathrm{H}_{2} \mathrm{O}_{2}$ about 4.2 to 4.5 times faster than $r \mathrm{CDH}$.

\section{Kinetic characterization of variant N700S}

Initial rates of substrate turnover were recorded over a substrate range of 0.003 to $10 \mathrm{mM}$ cellobiose for variant $\mathrm{N} 700 \mathrm{~S}$ and $r \mathrm{CDH}$ using DCIP, 1,4-benzoquinone and oxygen as electron acceptor. Kinetic data are summarized in Table 2. The catalytic constant $\left(\mathrm{k}_{\mathrm{cat}}\right)$ for cellobiose increased significantly for variant N700S compared to $r \mathrm{CDH}$. Without more detailed kinetic measurements it is difficult to discriminate if the mutation increases the rate of the reductive half-reaction (the oxidation of cellobiose and the concomitant reduction of FAD to $\mathrm{FADH}_{2}$ ) or increases the rate of $\mathrm{FADH}_{2}$ oxidation by electron acceptors in the oxidative half reaction. The increase of $k_{\text {cat }}$ was nearly identical for the two-electron acceptors DCIP (3.0fold) and 1,4-benzoquinone (3.1-fold) but higher for oxygen (4.5-fold). The $K_{M}$ values for cellobiose increased for N700S when compared to $r \mathrm{CDH}$ with DCIP (2.9-fold), 1,4-benzoquinone (2.5-fold) and oxygen (2.0-fold). The increased $K_{M}$ is most probably a kinetic effect and not due to changed affinities for the electron acceptors, which have no known binding site. The catalytic efficiencies $\left(\mathrm{k}_{\text {cat }} / \mathrm{K}_{\mathrm{M}}\right)$ for variant N700S and $r \mathrm{CDH}$ are similar for DCIP and 1,4-benzoquinone, but for oxygen the catalytic efficiency of N700S is 2.4-fold higher than for $r \mathrm{CDH}$. These data indicate that part of the increased substrate turnover comes from a faster reductive half-reaction, but in the case of oxygen also a faster oxidative half-raction is influencing the overall velocity. In conclusion, position N700 seems to influence both: substrate and oxygen turnover. In the homology model of M. thermophilum $\mathrm{CDH}$ (Figure 2) the amino acid N700 corresponds to the position of amino acid N688 in P. chrysosporium. This asparagine residue is positioned between the catalytic subsite $C$ and the binding subsite $B$ and with only minor positional changes in the cellobiose molecule it may interact with either of the subsites, thereby influencing substrate binding or catalysis. Due to the close vicinity to the catalytic base H689 it might also influence its proton abstracting properties. The comparative model of variant N700S shows that the serine side chain can easily flip its orientation between both subsites. To fully elucidate the influence of the mutation on the reaction mechanism more elaborate steadystate and presteady-state experiments are needed. The high substrate concentrations used in technological processes, which are much higher than the $K_{M}$ value of the $\mathrm{CDH}$ variant for cellobiose, ensures a 4.5 -fold increased turnover of the co-substrate $\mathrm{O}_{2}$. Under such conditions

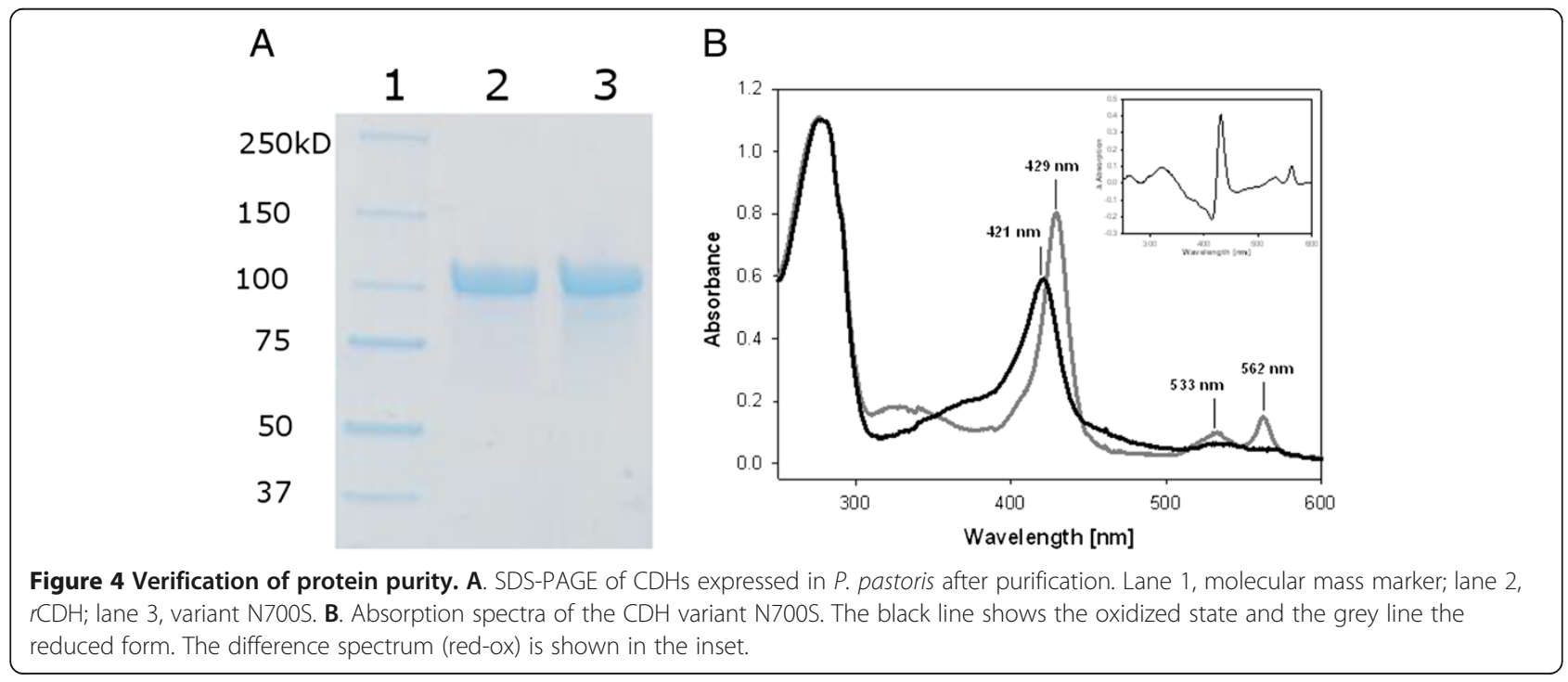




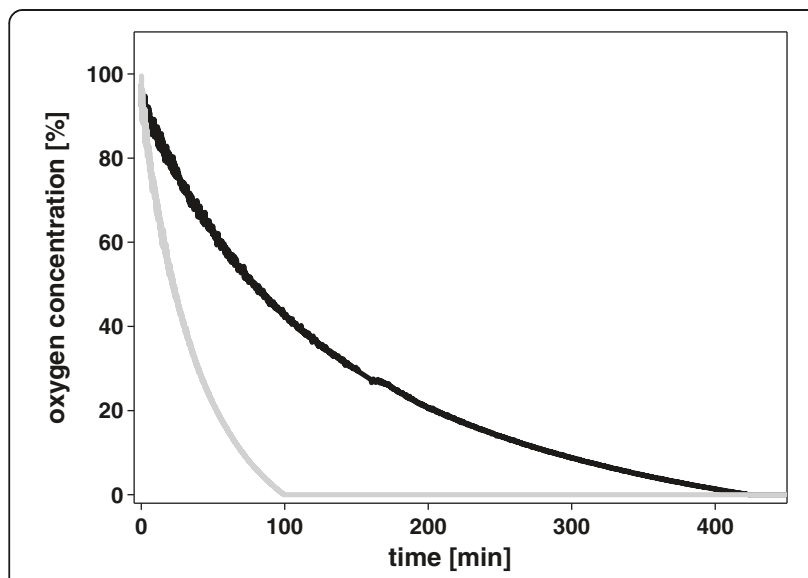

Figure 5 Measurement of the oxygen consumption rate of $r \mathrm{CDH}$ (grey line) and N700S (black line). Reactions were performed in a sealed microreactor containing $30 \mathrm{mM}$ cellobiose in $100 \mathrm{mM}$ Mcllvaine buffer, $\mathrm{pH}$ 6.0. The decrease of the $\mathrm{O}_{2}$ concentration was followed by an inert, luminescent sensor. An excess activity of catalase was added to disproportionate $\mathrm{H}_{2} \mathrm{O}_{2}$.

the obtained variant can be employed in 4-5 times lower amounts than the wild-type $\mathrm{CDH}$ to obtain the same amount of $\mathrm{H}_{2} \mathrm{O}_{2}$.

\section{Conclusions}

$S$. cerevisiae along with $E$. coli are the most successfully used host organisms for laboratory evolution and semirational protein engineering. The ease of genetic manipulation and its high transformation efficiencies due to the ability to maintain autonomously replicating plasmids facilitate the construction of mutant libraries. The successful expression of $\mathrm{CDH}$ under the control of the GAL1 promoter in S. cerevisiae offers a possibility to easily produce and screen for genetically engineered $\mathrm{CDH}$ variants and maybe also other mutated fungal oxidoreductases, which are needed for various biotechnological applications. The developed HTS assay can be easily adapted for other oxidase $\left(\mathrm{H}_{2} \mathrm{O}_{2}\right.$ forming $)$ activities. For production of

Table 2 Apparent kinetic constants of $r C D H$ and variant N700S

\begin{tabular}{llccc}
\hline & & \multicolumn{3}{c}{ Cellobiose } \\
\cline { 3 - 5 } $\begin{array}{l}\text { Electron } \\
\text { acceptor }\end{array}$ & Enzyme & $\mathbf{K}_{\mathbf{m}}(\boldsymbol{\mu M})$ & $\mathbf{k}_{\mathbf{c a t}}\left(\mathbf{s}^{-1}\right)$ & $\mathbf{k}_{\mathbf{c a t}} / \mathbf{K}_{\mathbf{m}}\left(\mathbf{M}^{-\mathbf{1}} \mathbf{s}^{-1}\right)$ \\
\hline DCIP & $r C D H$ & $11.4 \pm 0.7$ & $4.1 \pm 0.1$ & 360000 \\
\hline & $\mathrm{N} 700 S$ & $33 \pm 1$ & $12.4 \pm 0.6$ & 375000 \\
\hline 1,4 -benzoquinone & $r C D H$ & $22 \pm 1$ & $4.3 \pm 0.1$ & 185000 \\
\hline & $\mathrm{N} 7005$ & $56 \pm 2$ & $13.4 \pm 0.5$ & 240000 \\
\hline oxygen & $r C D H$ & $37 \pm 3$ & $0.042 \pm 0.003$ & 1100 \\
\hline & $\mathrm{N} 7005$ & $73 \pm 6$ & $0.19 \pm 0.01$ & 2600 \\
\hline
\end{tabular}

Kinetic constants for cellobiose were determined with DCIP, 1,4-benzoquinone and oxygen as electron acceptors at $\mathrm{pH} 6.0$ and $30^{\circ} \mathrm{C}$. selected variants $P$. pastoris is, however, the more efficient expression host.

The fact that most mutations at the selected positions resulted in inactive or less active $\mathrm{CDH}$ variants demonstrates that changes in the vicinity of the flavin have a tremendous impact on enzymatic activity. Out of the five selected amino acids only one mutation resulted in an increased $\mathrm{H}_{2} \mathrm{O}_{2}$ production. Further research towards an higher oxygen reactivity of $\mathrm{CDH}$ is definitely required for even more efficient cotton bleaching, laundry detergents or antimicrobial functionalization of medical devices.

\section{Methods}

\section{Chemicals and vectors}

Chemicals were purchased from Sigma, Fluka, Roth or VWR and were of the highest purity available. Primers (the nucleotide sequences are shown in Table 3) were obtained from VBC Biotech (Vienna, Austria). Restriction enzymes and T4-ligase were purchased from Fermentas, Phusion polymerase from New England Biolabs and the yeast expression vector pPICZ $\alpha \mathrm{A}$ from Invitrogen. The uracil independent and ampicillin resistance shuttle vector pJRoC30 was obtained from the Department of Biocatalysis (CSIC, Spain). Recombinant CDH $(r \mathrm{CDH})$ was produced as published [10].

\section{Strains and media}

The protease deficient S. cerevisiae strain BJ5465 was from LGC Promochem (Barcelona, Spain). SC drop-out plates (synthetic complete) contained $6.7 \mathrm{~g} \mathrm{~L}^{-1}$ yeast nitrogen base (YNB) without amino acids, $1.92 \mathrm{~g} \mathrm{~L}^{-1}$ yeast synthetic dropout medium supplement without uracil, $2 \%(\mathrm{w} / \mathrm{v})$ glucose, $25 \mathrm{mg} \mathrm{L}^{-1}$ chloramphenicol and $20 \mathrm{~g} \mathrm{~L}^{-1}$ agar. For the preparation of liquid minimal medium the agar was omitted and glucose was replaced by raffinose. The SG/R-CAA expression medium [37] contained $5 \mathrm{~g} \mathrm{~L}^{-1}$ casein hydrolysate, $9.67 \mathrm{~g} \mathrm{~L}^{-1} \mathrm{NaH}_{2} \mathrm{PO}_{4}, 6.77 \mathrm{~g} \mathrm{~L}^{-1} \mathrm{Na}_{2} \mathrm{HPO}_{4}, 2 \%$ (w/v) raffinose, $2 \%(\mathrm{w} / \mathrm{v})$ galactose, $0.5 \%(\mathrm{w} / \mathrm{v})$ glucose and $3.35 \%$ YNB. P. pastoris X-33 is a component of the EasySelect Pichia Expression Kit from Invitrogen. P. pastoris transformants were grown on YPD plates $\left(10 \mathrm{~g} \mathrm{~L}^{-1}\right.$ yeast extract, $20 \mathrm{~g} \mathrm{~L}^{-1}$ peptone, $10 \mathrm{~g} \mathrm{~L}^{-1}$ glucose and $100 \mathrm{mg} \mathrm{L}^{-1}$ zeocin) and the Basal Salts Medium (Invitrogen) was used for fermentation. The chemically competent $E$. coli strain NEB 5-alpha was purchased from New England Biolabs and used for maintenance and propagation of plasmids. E. coli cells were cultivated in Low Salt LB-medium (10 $\mathrm{g} \mathrm{L}^{-1}$ peptone from casein, $5 \mathrm{~g} \mathrm{~L}^{-1}$ yeast extract, $5 \mathrm{~g} \mathrm{~L}^{-1}$ $\mathrm{NaCl}$ and $25 \mathrm{mg} \mathrm{L}^{-1}$ zeocin).

\section{$\mathrm{CDH}$ expression in S. cerevisiae}

The published plasmid pMt1 [10] was used as template for the amplification of $M$. thermophilum $\mathrm{CDH}$ cDNA with 
Table 3 Nucleotide sequences of primers where $\mathrm{N}$ is $\mathrm{A} / \mathrm{T} /$ G/C and $\mathbf{S}$ is C/G

\begin{tabular}{ll}
\hline Primer name & Sequence (from $\mathbf{5}$ ' to $\mathbf{3}^{\text {') }}$ \\
\hline 5MT-BamHI & TATGGATCCATGAGAACTTCTTCTAGACTTATCG \\
\hline 5MT-XhoHI & TATCTCGAGCAGAATAACGTTCCAAACACC \\
\hline 3MT-XhoHI & TATCTCGAGTTACAAACATTGAGAGTACC \\
\hline 5MT-G323X & AGTCAATGCTNNSCTTTGTTCAAGCC \\
\hline 3MT-G323X & TTGAACCAAAGSNNAGCATTGACTGCG \\
\hline 5MT-A322X & TACCGCAGTCAATNNSGGTCTTTGGTTCAAGC \\
\hline 3MT-A322X & AACCAAAGACCAGCSNNGACTGCGGTACCTCC \\
\hline 3MT-L324X & AGTCAATGCTGGTNNSTGGTTCAAGCCATATTCTTGG \\
\hline 5MT-N700X & ACCAGCATTGACTGCGGTACCSNNACCAGCAT \\
\hline 3MT-N700X & CCAGTGSNAACAGACGTTCTNNSCACTGGATGGGTACTAACACGTCTGTTAG \\
\hline 5MT-H701X & AGACGTTCTAACNNSTGGATGGGTAC \\
\hline 3MT-H701X & GTACCCATCCASNNGTTAGAACGTCT \\
\hline 5MT-N700S & CAGACGTTCTTCTCACTGGATGGGTAC \\
\hline 3MT-N700S & AGAACGTCTGTTAGAAGGAGAC \\
\hline
\end{tabular}

two different forward primers (5MT-BamHI and 5MTXhoIfw) and the reverse primer 3MT-XhoI. The resulting nucleotide sequences encoded $\mathrm{CDH}$ with and without its native secretory leader sequence. The PCR amplicons were digested with the respective restriction enzymes and ligated into the equally treated shuttle vector pJRoC30 under the control of the GAL1 promotor. The resulting plasmid pJRoC30- $M t C D H$-nat encoded for the native secretory leader whereas in plasmid pJROC30- $M t C D H-\alpha$ it was replaced by the $\alpha$-factor prepro leader peptide of $S$. cerevisiae. Both plasmids were transformed into competent $S$. cerevisiae cells using the yeast transformation kit (Sigma). Transformed cells were plated on SC drop-out plates and incubated for 4 days at $30^{\circ} \mathrm{C}$. From each transformation 96 colonies were picked and cultured in a 96-well deep-well plate (Ritter) containing $100 \mu \mathrm{L}$ of minimal media per well. These master plates were sealed with Breathe -Easy film (Diversified Biotech) to prevent evaporation and incubated in a shaking incubator ( $480 \mathrm{rpm})$ at $25^{\circ} \mathrm{C}$ and a relative humidity of $80 \%$. After 48 h, $500 \mu \mathrm{L}$ of expression medium SG/R-CAA were added to each well and the plates were incubated for additional $120 \mathrm{~h}$. The cultivation was stopped by centrifugation for $5 \mathrm{~min}$ at $3000 \times$ g. From each well $50 \mu \mathrm{L}$ of clear culture supernatant were transferred from the master plate to 96-well plate assays using a pipetting robot (Janus, Perkin Elmer). The volumetric activity was measured with the DCIP-based assay.

\section{Preparation of libraries and HT-screening}

A comparative (homology) model of $M$. thermophilum $\mathrm{CDH}$ based on the template of $P$. chrysosporium $\mathrm{CDH}$ (1KDG, [7]) was used to select positions for mutagenesis.
The model was calculated by the Swiss-Model protein structure homology modeling server [38] accessible via the ExPASy web server and checked by using the ANOLEA mean force potential [39], the GROMOS empirical force field energy [40], the composite scoring function QMEAN [41] and a stereochemistry check [42]. Five amino acids located in close vicinity of the FAD cofactor (A322, G323, L324, N700 and H701) were selected for site-saturation mutagenesis. The plasmid pJRoC30-MtCDH-nat was used as template for the site-saturation PCRs, which allowed the construction of $c d h$ libraries containing all possible codons at the targeted position. Randomized NNS codons were used to reduce the bias of the genetic code. Mutants were prepared by the sequence overlap extension method [43]. Two complementary mutagenic oligonucleotide primers were designed for each of the 5 target positions (Table 3 ). The primers were used together with the flanking primers RMLC-sense and RMLN-antisense [44] to amplify two DNA fragments with overlapping ends. In a subsequent fusion PCR these fragments were assembled. PCR products of the mutated $c d h$ gene and flanking regions homologous to the vector were purified by electrophoresis, mixed with the XhoI and BamHI linearized vector pJRoC30 (ratio PCR product:vector $=4: 1$ ) and transformed into competent cells using the yeast transformation kit. For each of the five target positions a library of 352 clones was screened. Individual clones were picked and cultured under the abovementioned conditions. Four wells per plate were inoculated with $S$. cerevisiae transformed with pJRoC30-MtCDH-nat as a positive control, 2 wells were inoculated with $S$. cerevisiae transformed with empty pJRoC30 as a negative control and 2 wells were not inoculated at all. After $168 \mathrm{~h}$ of incubation the culture supernatants were subjected to the DCIP-based screening assay. Therefore, $50 \mu \mathrm{L}$ of each well were transferred from the master plate to two replica plates. $150 \mu \mathrm{L}$ of the respective assay mixture (DCIP-based assay and ABTS-based assay) were added by the liquidhandling-robot. Variants with increased $\mathrm{H}_{2} \mathrm{O}_{2}$ production were selected for rescreening. Each of the selected variants was used to inoculate four wells of a new cultivation plate, which was incubated and screened as described above. Exchanges in the nucleotide sequence of approved hits were checked by sequencing. Therefore, colony PCRs were performed using the primers RMLC-sense and RMLNantisense and the amplified fragments were sent for sequencing.

\section{HTS assays for enzymatic activity and $\mathrm{H}_{2} \mathrm{O}_{2}$ production}

$\mathrm{CDH}$ activity was measured by following the timedependent reduction of $300 \mu \mathrm{M}$ 2,6-dichloroindophenol (DCIP) at a wavelength of $520 \mathrm{~nm}\left(\varepsilon_{520}=6.8 \mathrm{mM}^{-1} \mathrm{~cm}^{-1}\right)$ in $100 \mathrm{mM}$ Mcllvaine buffer, $\mathrm{pH} 5.5$, containing $30 \mathrm{mM}$ cellobiose. The reaction was started by adding $150 \mu \mathrm{L}$ of the DCIP-based assay solution to $50 \mu \mathrm{L}$ sample in the well 
and followed in a temperature controlled plate reader at $30^{\circ} \mathrm{C}$ for $5 \mathrm{~min}$.

$\mathrm{H}_{2} \mathrm{O}_{2}$ production was measured by a modified 2,2'-azinobis(3ethylbenzthiazoline-6-sulfonate) (ABTS)-based assay. Originally, this assay quantifies the production of $\mathrm{H}_{2} \mathrm{O}_{2}$ by oxidases through the oxidation of ABTS in the presence of horseradish peroxidase. The formation of the green ABTS cation radical is followed spectrophotometrically at $420 \mathrm{~nm}\left(\varepsilon_{420}=36 \mathrm{mM}^{-1} \mathrm{~cm}^{-1}\right)$. However, because $\mathrm{CDH}$ can reduce the oxidized ABTS cation radical (like other electron acceptors), which would interfere with the assay, a modification was applied. First, $50 \mu \mathrm{L}$ of a reaction mixture containing $60 \mathrm{mM}$ cellobiose in $100 \mathrm{mM}$ Mcllvaine (citrate-phosphate) buffer, pH 5.5, was added to $50 \mu \mathrm{L}$ of the sample for the production of $\mathrm{H}_{2} \mathrm{O}_{2}$. The reaction mixture was incubated at $30^{\circ} \mathrm{C}$ for $4 \mathrm{~h}$ before $\mathrm{CDH}$ was inactivated at $90^{\circ} \mathrm{C}$ for $10 \mathrm{~min}$. This procedure does not influence the $\mathrm{H}_{2} \mathrm{O}_{2}$ concentration. The colorimetric reaction was started by the addition of $100 \mu \mathrm{L}$ of ABTS reagent containing $2 \mathrm{mM}$ ABTS and $5.7 \mathrm{U} \mathrm{mL}^{-1}$ peroxidase in $100 \mathrm{mM}$ Mcllvaine buffer, $\mathrm{pH}$ 5.5. The increase in absorbance was followed by a temperature controlled plate reader at $30^{\circ} \mathrm{C}$ for $5 \mathrm{~min}$. The stoichiometry for this reaction is two since for one mol of $\mathrm{H}_{2} \mathrm{O}_{2}$ two mol of the green ABTS cation radical are formed. The enzymatic activity is given in units $(\mathrm{U})$, which corresponds to the production of $1 \mu \mathrm{mol}$ cellobionic acid or $1 \mu \mathrm{mol} \mathrm{H}_{2} \mathrm{O}_{2}$ per min.

\section{Heterologous production of variant N700S in P. pastoris}

The plasmid pPICMtCDH was used as template for the generation of mutant N700S by a two-step mutagenesis approach using PCR and DpnI [45]. The sequences of the used primers $5 M t$-N700S and $3 M t$-N700S are given in Table 3. The mutation was confirmed by sequencing (LGC Genomics, Berlin, Germany). The SacI linearized expression plasmid was transformed into electrocompetent X-33 cells and transformants were selected on YPD zeocin plates $\left(1 \mathrm{mg} \mathrm{L}^{-1}\right)$. The integration of the gene was verified by colony PCR. A positive transformant was selected for production in a 7-L fermenter according to Harreither et al. [27].

\section{Protein purification}

The CDH variant N700S was purified by a hydrophobic interaction chromatography (HIC) and anion exchange chromatography (AIEX) according to a published procedure [10]. The purification was monitored by determination of total protein and activity. The purity of the enzyme preparation was verified by SDS-PAGE. The homogeneous $\mathrm{CDH}$ solution was sterile filtered, aliquoted and stored at $-80^{\circ} \mathrm{C}$ for characterization.

\section{Molecular properties}

SDS-PAGE was carried out using Mini-PROTEAN TGX precast gradient gels $(4-15 \%)$ and Bio-Safe Coomassie for staining (Bio-Rad Laboratories). Unstained Precision Plus Protein Standard was used for mass determination. All procedures were done according to the manufacturer's recommendations (Bio-Rad Laboratories). The spectra of homogeneously purified N700S were recorded at room temperature from 250 to $600 \mathrm{~nm}$ in both the oxidized and reduced state using a U-3000 Hitachi spectrometer (Tokyo, Japan). Spectra were recorded before and shortly after the addition of lactose to the cuvette. The oxidized spectrum was used for determining the purity represented by the ratio of $A_{420} / A_{280}$.

\section{Oxygen consumption rates}

A luminescence-based fiber optic sensor (PreSens $\mathrm{GmbH}$, Regensburg, Germany) was used to measure $\mathrm{O}_{2}$ consumption rates. Oxygen-saturated $100 \mathrm{mM}$ Mcllvaine buffer (oxygen concentration $\sim 1200 \mu \mathrm{M}$ ), $\mathrm{pH} 6.0$, containing $30 \mathrm{mM}$ cellobiose was magnetically stirred in a gas-tight, temperature controlled $\left(30^{\circ} \mathrm{C}\right)$ glass vial sealed by a septum (total volume $1870 \mu \mathrm{L}$ ). The reaction was started by adding $100 \mu \mathrm{L}$ of enzyme solution $\left(3.6 \mathrm{mg} \mathrm{mL}^{-1}\right.$ ) through a cannula.

\section{Kinetic measurements}

$\mathrm{CDH}$ activity was assayed using 2,6-dichloroindophenol (DCIP, $\left.\varepsilon_{520}=6.8 \mathrm{mM}^{-1} \mathrm{~cm}^{-1}\right)$ or 1,4-benzoquinone $\left(\varepsilon_{290}=\right.$ $\left.2.224 \mathrm{mM}^{-1} \mathrm{~cm}^{-1}\right)$ as electron acceptors. The reactions were followed for $180 \mathrm{sec}$ at $30^{\circ} \mathrm{C}$ in a Lambda $35 \mathrm{UV} / \mathrm{Vis} \mathrm{spec-}$ trophotometer. To assay $\mathrm{CDH}$ activity with oxygen as electron acceptor the modified ABTS assay described above was used. The reaction mixture for the production of $\mathrm{H}_{2} \mathrm{O}_{2}$ contained varying cellobiose concentrations (0.003 $10 \mathrm{mM}$ ) dissolved in $100 \mathrm{mM}$ McIlvaine buffer, $\mathrm{pH}$ 6.0, and $0.025 \mathrm{mg} \mathrm{mL}^{-1} r \mathrm{CDH}$ or $0.01 \mathrm{mg} \mathrm{mL}^{-1}$ of N700S. The reaction mixtures were incubated at $30^{\circ} \mathrm{C}$ and heat inactivated for 5 minutes at $90^{\circ} \mathrm{C}$. The color reaction was started by the addition of $100 \mu \mathrm{L}$ ABTS reagent. Catalytic constants were calculated using nonlinear least-squares regression by fitting the observed data to the Michaelis-Menten equation (Sigma Plot 11, Systat Software, Chicago, IL, USA). The protein concentration in fermentation and electrophoresis samples as well as of purified enzyme preparations was determined by Bradford's method using bovine serum albumin as standard and a prefabricated assay from Bio-Rad Laboratories (Hercules, CA).

\section{Additional file}

Additional file 1: Local alignment (Clustal X) of M. thermophilum

and $P$. chrysosporium flavodehydrogenase domains. Selected

positions for mutagenesis are indicated with arrows.

Competing interests

The authors declare that they have no competing interests. 


\section{Authors' contributions}

$\mathrm{CS}$ and RL planned the study and developed the scheme for highthroughput screening and enzyme characterization. MA selected the expression vector, strains and optimized yeast cultivations. PS and IK carried out the construction and screening of the site-saturation libraries, conducted the $P$. pastoris fermentation and purification of N700S. GG and GN measured the oxygen consumption and interpreted the data. CS wrote the first draft of the manuscript. MA and GG revised the manuscript. $R L$ and $C P$ coordinated the study, verified and interpreted results and revised the final manuscript. All authors have read and approved the final manuscript.

\section{Acknowledgements}

The authors thank the European Commission (FP7 243529-2-COTTONBLEACH) for financial support. CKP thanks the Austrian Science Fund (FWF) for financial support (grant P22094). IK is a member of the doctoral program BioToP (Biomolecular Technology of Proteins) of the Austrian Science Fund (FWF; W1224). MA thanks the Spanish Government for financial support (BIO2010-19697).

\section{Author details}

${ }^{1}$ Vienna Institute of Biotechnology, Department of Food Sciences and Technology, BOKU-University of Natural Resources and Life Sciences, Vienna, Austria. ${ }^{2}$ Department of Biocatalysis, Institute of Catalysis, CSIC, 28049 Madrid, Spain. ${ }^{3}$ Institute of Environmental Biotechnology, University of Natural Resources and Life Sciences, Vienna, Austria.

Received: 18 February 2013 Accepted: 14 April 2013

Published: 23 April 2013

\section{References}

1. Harreither W, Sygmund C, Augustin M, Narciso M, Rabinovich ML, Gorton L, Haltrich D, Ludwig R: Catalytic properties and classification of cellobiose dehydrogenases from ascomycetes. Appl Environ Microbiol 2011, 77:1804-1815.

2. Beeson WT, Phillips CM, Cate JHD, Marletta MA: Oxidative cleavage of cellulose by fungal copper-dependent polysaccharide monooxygenases. J Am Chem Soc 2012, 134:890-892.

3. Langston JA, Shaghasi T, Abbate E, Xu F, Vlasenko E, Sweeney MD: Oxidoreductive cellulose depolymerization by the enzymes cellobiose dehydrogenase and glycoside hydrolase 61. App/ Environ Microbiol 2011, 77:7007-7015.

4. Phillips CM, Beeson WT, Cate JH, Marletta MA: Cellobiose dehydrogenase and a copper-dependent polysaccharide monooxygenase potentiate cellulose degradation by Neurospora crassa. ACS Chem Biol 2011, 6:1399-1406.

5. Sygmund C, Kracher D, Scheibelbrandner S, Zahma K, Felice AK, Kittl R, Harreither W, Ludwig R: Charecterization of the two Neurospora crassa cellobiose dehydrogenases and their connection to oxidative cellulose degradation. Appl Environ Microbiol 2012, 78:6161-6171.

6. Hallberg BM, Bergfors T, Baeckbro K, Pettersson G, Henriksson G, Divne C: A new scaffold for binding haem in the cytochrome domain of the extracellular flavocytochrome cellobiose dehydrogenase. Structure 2000, 8:79-88.

7. Hallberg MB, Henriksson G, Pettersson G, Divne C: Crystal structure of the flavoprotein domain of the extracellular flavocytochrome cellobiose dehydrogenase. J Mol Biol 2002, 315:421-434.

8. Ludwig R, Ortiz R, Schulz C, Harreither W, Sygmund C, Gorton L: Cellobiose dehydrogenase modified electrodes: advances by materials science and biochemical engineering. Anal Bioanal Chem 2013, 405:3637-3658

9. Zámocký M, Ludwig R, Peterbauer C, Hallberg BM, Divne C, Nicholls P, Haltrich D: Cellobiose dehydrogenase - A flavocytochrome from wooddegrading, phytopathogenic and saprotropic fungi. Curr Protein Pept Sci 2006, 7:255-280.

10. Flitsch A, Prasetyo EN, Sygmund C, Ludwig R, Nyanhongo GS, Guebitz GM: Cellulose oxidation and bleaching processes based on recombinant Myriococcum thermophilum cellobiose dehydrogenase. Enzyme Microb Technol 2013, 52:60-67.

11. Ludwig R, Harreither W, Tasca F, Gorton L: Cellobiose dehydrogenase: a versatile catalyst for electrochemical applications. Chemphyschem 2010, 11:2674-2697.

12. Ludwig R, Ozga M, Zámocky M, Peterbauer C, Kulbe KD, Haltrich D Continuous enzymatic regeneration of electron acceptors used by flavoenzymes: Cellobiose dehydrogenase-catalyzed production of labtobionic acid as an example. Biocatal Biotransformation 2004, 22:97-104.
13. Van Hecke W, Ludwig R, Dewulf J, Auly M, Messiaen T, Haltrich D, Van Langenhove $\mathrm{H}$ : Bubble-free oxygenation of a bi-enzymatic system: effect on biocatalyst stability. Biotechnol Bioeng 2009, 102:122-131.

14. Van Hecke W, Ludwig R, Dewulf J, Haltrich D, Van Langenhove H: Green oxidation of renewable carbohydrates: lactobionic acid production as an example. Commun Agric Appl Biol Sci 2008, 73:9-13.

15. Ciullini I, Tilli S, Scozzafava A, Briganti F: Fungal laccase, cellobiose dehydrogenase, and chemical mediators: combined actions for the decolorization of different classes of textile dyes. Bioresour Technol 2008, 99:7003-7010.

16. Cameron MD, Aust SD: Cellobiose dehydrogenase - An extracellular fungal flavocytochrome. Enzyme Microb Technol 2001, 28:129-138.

17. Pricelius S, Ludwig R, Lant N, Haltrich D, Guebitz GM: Substrate specificity of Myriococcum thermophilum cellobiose dehydrogenase on monooligo-, and polysaccharides related to in situ production of $\mathrm{H}_{2} \mathrm{O}_{2}$. App Microbiol Biotechnol 2009, 85:75-83.

18. Pricelius S, Ludwig R, Lant NJ, Haltrich D, Guebitz GM: In situ generation of hydrogen peroxide by carbohydrate oxidase and cellobiose dehydrogenase for bleaching purposes. Biotechnol J 2010, 6:224-230.

19. Ribitsch D, Karl W, Wehrschütz-Sigl E, Tutz S, Remler P, Weber HJ, Gruber K Stehr R, Bessler C, Hoven N, et al: Heterologous expression and characterization of choline oxidase from the soil bacterium Arthrobacter nicotianae. Appl Microbiol Biotechnol 2009, 81:875-886.

20. Tzanov T, Costa SA, Gübitz GM, Cavaco-Paulo A: Hydrogen peroxide generation with immobilized glucose oxidase for textile bleaching J Biotechnol 2002, 93:87-94

21. Nyanhongo GS, Sygmund C, Ludwig R, Prasetyo EN, Guebitz GM: An antioxidant regenerating system for continuous quenching of free radicals in chronic wounds. Eur J Pharm Biopharm 2013.

22. Nyanhongo GS, Sygmund C, Ludwig R, Prasetyo EN, Guebitz GM: Synthesis of multifunctional bioresponsive polymers for the management of chronic wounds. J Biomed Mater Res B Appl Biomater 2013, 83:396-404.

23. Chaiyen $P$, Fraaije MW, Mattevi $A$ : The enigmatic reaction of flavins with oxygen. Trends Biochem Sci 2012, 37:373-380.

24. Mattevi A: To be or not to be an oxidase: challenging the oxygen reactivity of flavoenzymes. Trends Biochem Sci 2006, 31:276-283.

25. McDonald CA, Fagan RL, Collard F, Monnier VM, Palfey BA: Oxygen reactivity in flavoenzymes: context matters. J Am Chem Soc 2011, 133:16809-16811.

26. Bey M, Berrin JG, Poidevin L, Sigoillot JC: Heterologous expression of Pycnoporus cinnabarinus cellobiose dehydrogenase in Pichia pastoris and involvement in saccharification processes. Microb Cell Fact 2011, 10:113.

27. Harreither W, Felice AKG, Paukner R, Gorton L, Ludwig R, Sygmund C: Recombinantly produced cellobiose dehydrogenase from Corynascus thermophilus for glucose biosensors and biofuel cells. Biotechnol J 2012, 7:1359-1366.

28. Zhang R, Fan Z, Kasuga T: Expression of cellobiose dehydrogenase from Neurospora crassa in Pichia pastoris and its purification and characterization. Protein Expr Purif 2011, 75:63-69.

29. Desriani, Ferri S, Sode K: Functional expression of Phanerochaete chrysosporium cellobiose dehydrogenase flavin domain in Escherichia coli. Biotechnol Lett 2010, 32:855-859.

30. Alcalde M: Mutagenesis protocols in Saccharomyces cerevisiae by in vivo overlap extension. Methods Mol Biol 2010, 634:3-14.

31. Gonzalez-Perez D, Garcia-Ruiz E, Alcalde M: Saccharomyces cerevisiae in directed evolution: an efficient tool to improve enzymes. Bioeng Bugs 2012, 3:172-177.

32. Brake AJ: a-Factor leader-directed secretion of heterologous proteins from yeast. In Methods Enzymol. Volume 185. Edited by David VG. Waltham: Academic Press; 1990:408-421.

33. Camarero S, Pardo I, Cañas Al, Molina P, Record E, Martínez AT, Martínez MJ, Alcalde M: Engineering platforms for directed evolution of laccase from Pycnoporus cinnabarinus. Appl Environ Microbiol 2012, 78:1370-1384

34. Garcia-Ruiz E, Gonzalez-Perez D, Ruiz-Duenas FJ, Martinez AT, Alcalde M: Directed evolution of a temperature-, peroxide- and alkaline $\mathrm{pH}$-tolerant versatile peroxidase. Biochem J 2012, 441:487-498.

35. Mate D, Garcia-Burgos C, Garcia-Ruiz E, Ballesteros AO, Camarero S, Alcalde M: Laboratory evolution of high-redox potential laccases. Chem Biol 2010, 17:1030-1041.

36. Arnold F, Georgiou G: Directed Enzyme Evolution: screening and selection methods, Methods in Molecular Biology. Totowa, New Jersey: Humana Press; 2003:231. 
37. Bowley DR, Labrijn AF, Zwick MB, Burton DR: Antigen selection from an HIV-1 immune antibody library displayed on yeast yields many novel antibodies compared to selection from the same library displayed on phage. Protein Eng Des Sel 2007, 20:81-90.

38. Arnold K, Bordoli L, Kopp J, Schwede T: The SWISS-MODEL workspace: a web-based environment for protein structure homology modelling. Bioinformatics 2006, 22:195-201.

39. Melo F, Feytmans E: Assessing protein structures with a non-local atomic interaction energy. J Mol Biol 1998, 277:1141-1152.

40. Christen M, Hünenberger PH, Bakowies D, Baron R, Bürgi R, Geerke DP, Heinz TN, Kastenholz MA, Kräutler V, Oostenbrink C, et al: The GROMOS software for biomolecular simulation: GROMOS05. J Comput Chem 2005, 26:1719-1751.

41. Benkert P, Tosatto SCE, Schomburg D: QMEAN: a comprehensive scoring function for model quality assessment. Proteins 2008, 71:261-277.

42. Laskowski RA, MacArthur MW, Moss DS, Thornton JM: PROCHECK: a program to check the stereochemical quality of protein structures. J Appl Crystallogr 1993, 26:283-291.

43. Ho SN, Hunt HD, Horton RM, Pullen JK, Pease LR: Site-directed mutagenesis by overlap extension using the polymerase chain reaction. Gene 1989, 77:51-59.

44. Garcia-Ruiz E, Mate D, Ballesteros A, Martinez AT, Alcalde M: Evolving thermostability in mutant libraries of ligninolytic oxidoreductases expressed in yeast. Microb Cell Fact 2010, 9:17.

45. Li S, Wilkinson MF: Site-directed mutagene sis: a two-step method using PCR and Dpnl. Biotechniques 1997, 23:588-590.

\section{Submit your next manuscript to BioMed Central and take full advantage of:}

- Convenient online submission

- Thorough peer review

- No space constraints or color figure charges

- Immediate publication on acceptance

- Inclusion in PubMed, CAS, Scopus and Google Scholar

- Research which is freely available for redistribution 